\title{
Doença por Coronavírus 2019: desafios emergentes e o ensino odontológico brasileiro
}

\author{
Matheus dos Santos Fernandez*; Nathalia Ribeiro Jorge da Silva**; Vanessa dos Santos \\ Viana***; Cristiane Costa da Cunha Oliveira****
}

* Estudante, Faculdade de Odontologia, Universidade Federal de Pelotas

** Mestranda, Programa de Pós-Graduação em Odontologia, Universidade Federal de Pelotas

*** Mestre, Programa de Pós-Graduação em Odontologia, Universidade Federal de Sergipe; Professora do Curso de Odontologia, Universidade Tiradentes

**** Doutora, Professora adjunta no Programa de PósGraduação em Saúde e Ambiente, Universidade Tiradentes

Recebido em 23/05/2020. Aprovado em 25/05/2020.

\begin{abstract}
RESUMO
A doença por coronavírus (COVID-19) surgiu na China no final de 2019, disseminando-se rapidamente por mais de 200 países. Devido às características dos ambientes e procedimentos odontológicos, há um maior risco de infecção cruzada entre a equipe de saúde bucal e os usuários desse serviço. Para consultórios odontológicos, escolas de Odontologia e seus hospitais associados, localizados em áreas que são (potencialmente) afetadas pela COVID-19, protocolos rigorosos e eficazes de controle de infecção estão sendo urgentemente desenvolvidos pelas agências reguladoras competentes, tanto a nível nacional, quanto internacional. Além disso, a pandemia teve um impacto imediato e dramático na educação odontológica, visto que nesse momento as instituições estão à frente do desafio de reorganizar sua infraestrutura e seus métodos de ensino para encarar as possíveis consequências dessa nova realidade, preservando e fomentando o progresso contínuo de seus futuros profissionais. Nesse sentido, o objetivo deste estudo é apresentar importantes informações relacionadas à nova síndrome respiratória aguda por coronavírus-2 e seu impacto na Odontologia, abordando as principais orientações de biossegurança que devem ser adotadas nos atendimentos clínicos, bem como discutir as mudanças no ensino odontológico brasileiro frente à pandemia de COVID-19.
\end{abstract}

Descritores: COVID-19. Infecções por Coronavírus. Controle de Infecção. Odontologia. Ensino Odontológico. 


\section{INTRODUÇÃO}

Uma nova doença causada por uma cepa de coronavírus (COVID-19) foi identificada na china no final de 2019 e, em virtude da sua rápida disseminação em escala global, a Organização Mundial da Saúde OMS) anunciou que esse surto constituíra uma emergência de saúde pública de interesse internacional ${ }^{1}$. Surtos anteriores de coronavírus incluem a síndrome respiratória aguda grave (SARS-CoV) e a síndrome respiratória do Oriente Médio (MERS-CoV), responsáveis por centenas de mortes na China e Arábia Saudita, respectivamente. Todavia, a síndrome respiratória aguda grave-2 parece ser mais infeciosa e letal comparada com as síndromes anteriores ${ }^{2}$.

Pesquisas focadas no desenvolvimento de vacinas e opções de tratamento contra o SARS CoV-2 estão sendo desenvolvidas, mas certamente não estarão disponíveis para auxiliar no combate desta primeira onda da pandemia ${ }^{3}$. Enquanto isso, a humanidade continua sendo afetada por profundas mudanças no modelo de produção, no comportamento social e nas condições econômicas no cenário mundial ${ }^{4}$. A Odontologia, assim como outros campos das ciências da saúde e demais setores produtivos, repensaram seus processos de trabalho à luz da realidade pandêmica ${ }^{4-7}$.

A equipe de saúde bucal está entre os grupos profissionais com maiores riscos de serem infectados por COVID-19 e tornarem-se possíveis vetores de transmissão comunitária ${ }^{8}$. No Brasil, a realização de tratamentos não emergenciais está suspensa e a maioria das escolas de Odontologia do país estão com suas atividades interrompidas ${ }^{9,10}$. Com isso, nesse momento é oportuno que ocorram modificações na prestação de atividades de educação e atendimento odontológico, a fim de salvaguardar a saúde dos pacientes, estudantes e funcionários, mantendo atenção no controle das mudanças no ambiente e políticas locais ou nacionais e sustentando o progresso acadêmico dos alunos $^{6}$.
As pessoas envolvidas em atividades odontológicas precisam estar cientes quanto às características da COVID-19, suas maneiras de transmissão e medidas de proteção necessárias para prestar atendimento durante e após à pandemia ${ }^{8,11}$. Nesse sentido, o presente estudo tem como objetivo apresentar importantes informações acerca da doença de coronavírus e seu impacto na Odontologia, destacando as principais orientações de biossegurança, bem como discutir as novas alterações no ensino odontológico brasileiro frente à pandemia de COVID-19.

\section{SÍNDROME RESPIRATÓRIA AGUDA POR CORONAVÍRUS}

Uma doença viral capaz de desencadear problemas respiratórios como pneumonia, tosse seca e dispneia surgiu na China no final de $2019^{12}$. $\mathrm{O}$ crescente aumento de novos casos em escala mundial despertou uma grande preocupação dos órgãos de saúde ${ }^{5}$. Análises genéticas identificaram o patógeno da doença como uma nova cepa de coronavírus $(\mathrm{CoV})$, cujo hospedeiro natural de origem é o morcego ${ }^{13}$.

A transmissão do vírus entre os seres humanos pode ocorrer através da transmissão direta (tosse, espirro e inalação de gotículas contaminadas) e por meio do contato cruzado com as vias oral, nasal, mucosas oculares e através de superfícies ambientais contaminada. Ademais, a COVID-19 também pode ser comprovadamente transmitida direta ou indiretamente pela saliva ${ }^{8}$. Não há evidências de uma rota de transmissão vertical, entretanto pesquisadores discutem a plausibilidade uma rota de infecção do SARSCoV-2 por meio de matéria orgânica fecal, afetando principalmente comunidades socialmente vulneráveis sem acesso às condições adequadas de saneamento básico ${ }^{14}$. Ainda neste contexto, é importante destacar que a transmissão do vírus pode ocorrer pelo contato com pacientes assintomáticos, o que requer ainda atenção no 
cuidado da transmissão, visto que todos os indivíduos devem ser considerados potenciais contaminados ${ }^{15}$.

No início de 2020, o novo surto do SARSCoV-2 foi determinado como uma emergência de saúde pública de interesse internacional pela OMS, sendo declarado oficialmente o surgimento de uma nova pandemia, conhecida como doença causada pelo novo coronavírus ${ }^{16}$. Apesar disso, até 23 de maio de 2020 - 6:39pm -, a OMS já contabilizou globalmente cerca de 5.105 .881 casos confirmados, com mais de 333.446 mortes. O Brasil é o segundo maior país com o maior número de casos (310.087) e mortes atribuídas a COVID$19(22.013)^{17}$.

\section{O IMPACTO DA COVID-19 NA ODONTOLOGIA}

O impacto da COVID-19 está modificando a manutenção dos serviços de saúde, tornando necessária a discussão da adaptação de métodos e ferramentas de trabalho inovadoras, visto que os profissionais da área da saúde apresentam risco potencial de infecção durante a prática clínica ${ }^{18}$. Wang et al. (2020) realizaram um estudo para avaliar as características de pacientes chineses hospitalizados por COVID-19 e demonstraram que $29 \%$ dos internados eram profissionais de saúde da linha de frente contra a pandemia ${ }^{19}$.

Embora a Odontologia assuma um papel secundário nesse momento, os pacientes e a equipe de saúde bucal podem ser expostos a microorganismos patogênicos (vírus e bactérias) que afetam a cavidade bucal e o trato respiratório dos indivíduos ${ }^{20}$. As peculiaridades do atendimento odontológico contribuem para um maior risco de infecção dos profissionais devido à especificidade dos procedimentos que envolvem comunicação face a face com os pacientes, exposição frequente à saliva, sangue e outros fluídos corporais, bem como o manuseio de instrumentais pérfuro-cortantes ${ }^{21}$.

A disseminação aérea do SARS-CoV é um fato bem relatado na literatura, pois estudos odontológicos mostram que diversos procedimentos realizados no consultório produzem meios para a disseminação do vírus no ambiente clínico $^{22}$. No momento em que alguns dispositivos dentários, como canetas de alta e baixa rotação, entram em funcionamento, uma grande quantidade de aerossol e gotículas misturadas com a saliva ou sangue do paciente será gerada ${ }^{20}$. Essas micropartículas e/ou aerossóis são pequenos o suficiente para permanecerem no meio aéreo um longo período antes de se instalarem em superfícies ambientais ou até serem inalados no trato respiratório ${ }^{23}$.

Os estudos de Van Doremalen et al. (2020) e Peng et al. (2020) demostraram que o SARS-CoV-

2 manteve-se infeccioso em aerossóis gerados experimentalmente, apresentando uma redução no potencial de infecção somente após um período de três horas ${ }^{23,24}$. Com isso, a transmissão por meio de gotículas e aerossóis contaminados torna-se mais uma preocupação constante em clínicas dentárias e hospitais odontológicos universitários, considerando que é difícil evitar a geração de grandes quantidades de aerossóis contaminados por fluídos infectados ${ }^{18}$. Essas condições exigem maior cuidado com a organização do consultório, da mesma forma como sugerem cautela durante $o$ atendimento clínico, e a correta desinfecção dos instrumentais e equipamentos de trabalho ${ }^{20}$.

Khader et al. (2020) avaliaram o nível de consciência, percepção e atitude em relação à COVID-19 e controle de infecção em dentistas jordanianos e observaram que embora os profissionais do país estivessem cientes dos sintomas, modo de transmissão e medidas de controle de infecção pelo vírus, muitos apresentavam uma compreensão limitada das medidas extras de precaução que protegem a equipe odontológica e outros pacientes da COVID1925. De modo semelhante, em seu estudo de abordagem multinacional, Kamate et al. (2020) 
observaram que os melhores escores de conhecimento, atitudes e práticas odontológicas estiveram associadas ao maior grau de qualificação e anos de prática clínica ${ }^{26}$.

Os impactos da pandemia na Odontologia são variados, principalmente porque o período de isolamento social limita a prática clínica ${ }^{27}$. Isso pode influir na sobrecarga dos serviços de saúde devido à demanda reprimida, no agravo das condições clínicas e na organização do atendimento em saúde bucal, bem como pode acarretar inúmeras perdas financeiras para os profissionais da Odontologia ${ }^{11,27}$.

\section{ATENDIMENTO ODONTOLÓGICO E MEDIDAS DE BIOSSEGURANÇA}

As experiências dos profissionais de saúde bucal na prática clínica variaram consideravelmente dependendo do contexto social $^{6}$. Nações europeias começaram a implementar a restrição de acesso da população aos consultórios odontológicos. Nesses países, as instituições acadêmicas de Odontologia adotaram modificações oportunas na prestação de educação e atendimento clínico, a fim de manter o atendimento à população e a continuidade do ensino ${ }^{7}$.

No Brasil, país da América Latina com maior número de infectados e óbitos por COVID19, o Ministério da Saúde optou por autorizar a realização dos procedimentos de urgência no Sistema Único de Saúde (SUS) e pela limitação dos procedimentos não-eletivos na atividade autônoma ${ }^{9}$. Os cursos de Odontologia das instituições públicas do país, responsáveis pela realização de uma considerável parcela de atendimentos em saúde bucal para a população brasileira, estão com as suas atividades acadêmicas interrompidas em virtude da necessidade de adaptação de sua metodologia de ensino e sua infraestrutura de forma que possam receber seus estudantes e a população com segurança $^{28}$.

Órgãos nacionais como a Agência Nacional de Vigilância Sanitária (ANVISA) ${ }^{29}$ e o Conselho Federal de Odontologia $(\mathrm{CFO})^{30}$, da mesma forma como importantes instituições internacionais como a American Dental Association (ADA) ${ }^{31}$ e o Center Disease Control and Prevention $(C D C)^{32}$, publicaram diretrizes para a orientação do atendimento odontológico. De modo geral, as medidas sugeridas são voltadas para o manejo biosseguro do paciente e equipe de trabalho, englobando diversas alterações que os profissionais devem adotar no replanejamento do espaço físico do consultório e nos procedimentos técnicos realizados.

Durante o surto pandêmico, os procedimentos eletivos devem ser evitados por pelo menos duas semanas se o indivíduo apresentar sintomas ou histórico de exposição conhecido e não ser realizado em indivíduos positivos para SARS-CoV-2 ${ }^{5,30}$. A suspensão do tratamento não emergencial é recomendada, enquanto outros quadros clínicos emergenciais, como drenagem purulenta externa, dor grave e hemorragia, devem receber a máxima atenção pelo cirurgião-dentista ${ }^{29,31,32}$. O quadro 1 apresenta algumas condições clínicas eletivas e não-eletivas ao tratamento odontológico durante esse período.

Quando o diagnóstico das condições emergenciais for realizado, as principais medidas de biossegurança devem ser cautelosamente adotadas nos atendimentos clínicos, principalmente durante a expansão no número de casos infectados por COVID-19 (quadro 2).

Meng et al. (2020) descreveram as medidas de biossegurança adotadas no Hospital Escola de Estomatologia da Universidade de Wuhan (HEUW), China. Antes da implementação das novas medidas de proteção, casos de infecção cruzada entre pacientes e dois enfermeiros do hospital foram confirmados. A infecção foi 
possivelmente limitada apenas a esses sujeitos porque as estratégias de prevenção biosseguras utilizadas durante o trabalho clínico dos demais profissionais da saúde impediram a transmissão da doença. Além das medidas citadas no quadro 1, a equipe do HEUW realizou divisões nos setores do hospital-escola, de acordo com os níveis de infecção ambiental e o acesso aos diferentes setores por um mesmo indivíduo era intermediado por rigorosos protocolos de desinfecção ${ }^{5}$.

Quadro 1. Apresentação de casos clínicos de acordo com a necessidade de tratamento de urgência e emergência durante a pandemia de COVID-19

\begin{tabular}{|c|c|}
\hline TRATAMENTOS NÃO-ELETIVOS & TRATAMENTOS ELETIVOS \\
\hline Dor dentária intensa por inflamação pulpar & Profilaxia de rotina \\
\hline Pericoronarite ou dor no terceiro molar & Dor dentária leve \\
\hline Osteíte pós-operatória, troca de curativos de cavidade seca & Manutenção do tratamento periodontal \\
\hline $\begin{array}{l}\text { Abscesso ou infecção bacteriana localizada, resultando em dor } \\
\text { e edema localizados }\end{array}$ & Procedimentos odontológicos com finalidade estética \\
\hline $\begin{array}{l}\text { Fratura dentária resultando em dor ou causando trauma nos } \\
\text { tecidos moles }\end{array}$ & $\begin{array}{l}\text { Restauração de dentes incluindo tratamento de lesões } \\
\text { cariosas assintomáticas }\end{array}$ \\
\hline Trauma dentário com avulsão / luxação & $\begin{array}{l}\text { Cirurgias (exodontia de dentes e cirurgias periodontais } \\
\text { assintomáticas, implantodontia, ortognática, entre outras) }\end{array}$ \\
\hline $\begin{array}{l}\text { Cimentação final de coroa / prótese fixa se a restauração } \\
\text { temporária for perdida, quebrada ou causar irritação gengival }\end{array}$ & Tratamento de lesões cervicais não cariosas \\
\hline $\begin{array}{l}\text { Substituição de selamento temporário nas aberturas de acesso } \\
\text { endodôntico em pacientes com dor }\end{array}$ & Ajustes protéticos \\
\hline $\begin{array}{l}\text { Recorte ou ajuste de um fio ou aparelhos ortodônticos que } \\
\text { perfuram ou ulceram a mucosa oral }\end{array}$ & \\
\hline
\end{tabular}

Fonte: American Dental Association

Embora a biossegurança seja essencial e a base de todo atendimento odontológico, não é ministrada como uma disciplina obrigatória em várias instituições de ensino do Brasil. Os estudantes adquirem os conhecimentos necessários para evitar a transmissão de doenças nas primeiras disciplinas do curso, nas quais são apresentados aos atendimentos aos pacientes.

Em uma pesquisa realizada por Arantes et al. (2015), alguns acadêmicos brasileiros do curso de Odontologia, apesar de terem noção do risco de infecção cruzada, relataram que não executam as normas de biossegurança previstas pela ANVISA, pelo Ministério da Saúde e pelo manual de biossegurança das instituições ${ }^{33}$. Uma recente revisão sistemática e metanálise que incluiu estudos do Brasil, Reino Unido e França, avaliando a aderência de estudantes de instituições odontológicas na adoção de procedimentos de higiene, também não apresentou informações animadoras e constatou que a higiene das mãos nem sequer era realizada por $50 \%$ do número total de alunos $^{34}$.

\section{O ENSINO ODONTOLÓGICO E A PANDEMIA DE COVID-19}

A formação em Odontologia é um tradicional e importante curso de graduação da área das ciências da saúde no Brasil. A carga horária mínima da graduação é de 4.000 horas, sendo que grande parte dela deve ser destinada ao atendimento de pacientes por meio de atividades práticas laboratoriais em ambulatórios e clínicas odontológicas ${ }^{35}$. 
Quadro 2. Recomendações básicas para o atendimento odontológico durante a pandemia de COVID19

\begin{abstract}
TRIAGEM DE RISCO
- A triagem de risco criteriosa deve ser realizada para avaliar a presença de sintomas de COVID-19 e avaliar a exposição anterior a situações de risco, como viagens recentes e histórico de contato entre humanos. Além disso, através da triagem de risco é possível estabelecer a avaliação do quadro de urgência e as possibilidades de tratamento. A comunicação inicial deve ser estabelecida por meio de ligações telefônicas ou pelo uso de aplicativos digitais que possibilitem o envio de arquivos de imagem e vídeo (WhatsApp, Instagram, Skype, entre outros).

\section{SALA DE ESPERA}

- A sala de espera deve apresentar um ambiente com dimensionamento de 1,2 metros por pessoa, com ventilação constante e distanciamento mínimo de 1 metro entre as cadeiras. Na entrada do local deve ser instalado um tapete bactericida e dispensadores com álcool em gel ou solução à base de álcool $70 \%$ para higienização das mãos. Deve-se evitar o uso compartilhado de materiais como canetas e pranchetas, sendo que as revistas, jornais e materiais coletivos da sala de espera devem ser retirados. A permanência de acompanhantes deve ocorrer somente em casos específicos, como no atendimento de pacientes com necessidades especiais, crianças e idosos.
\end{abstract}

\title{
CONSULTÓRIO ODONTOLÓGICO
}

- O ambiente clínico deve ser fechado, com área mínima de $9 \mathrm{~m}^{2}$. Consultórios coletivos devem ter no mínimo a distância de 0,8 metros nas cabeceiras e $1 \mathrm{~m}$ nas laterais de cada cadeira, entre 2 cadeiras deve haver a distância de 2 metros, com uma barreira mecânica entre essas. Os boxes individuais em clínicas coletivas devem ser isolados, evitando a propagação dos aerossóis.

- Superfícies como bancadas e carrinho auxiliar devem ser cobertas por campos descartáveis e impermeáveis. Seringas tríplices devem ter pontas descartáveis.

- Preferir radiografias extraorais, como a panorâmica ou tomografia computadorizada por feixe cônico às intraorais para a redução do estímulo à salivação e tosse.

- Deve ser realizada a aspiração contínua da saliva residual e se possível com sistema de sucção de alta potência (bomba a vácuo).

\section{ATENDIMENTO CLÍNICO}

- Os profissionais devem realizar os atendimentos odontológicos com avental impermeável, touca, luvas, máscara cirúrgica e proteções de superfícies que devem ser utilizados durante os atendimentos e descartados após cada atendimento em lixeira de conteúdo infectante. Óculos e protetores faciais (face shields) devem ser utilizados nos atendimentos às pessoas com síndrome gripal, dentro do consultório, podendo serem desinfetados e reutilizados após cada consulta. Em procedimentos em que ocorre a geração de aerossóis, recomenda-se obrigatoriamente o uso de respirador facial (máscaras N95 ou similares). - Para diminuir a infecção durante o atendimento clínico, o bochecho pré-procedimento com peróxido de hidrogênio 0,5 a $1 \%$ ou solução aquosa de iodo polvidona $0,2 \%$ é essencial. $\mathrm{O}$ atendimento deve ser realizado a quatro mãos e o controle da produção de aerossóis deve ser feito com a utilização de materiais manuais, uso de dique de borracha e uso de sugador e aspirador de alta potência, sempre evitando o uso de ultrassom, jato de bicarbonato, canetas de alta e baixa rotação, seringa de 3 vias e ejetores de saliva de alto volume.

\section{LIMPEZA E DESINFECÇÃO}

- A limpeza da área mais contaminada do consultório, região composta pela cadeira e mocho odontológico, cuspideira, mangueiras, cabos elétricos e demais equipamentos periféricos manuseados pelo dentista ou auxiliar, deve ser realizada com uso de água e sabão neutro e a desinfecção realizada com hipoclorito de sódio a 1\% ou álcool 70\%. As paredes e pisos deverem ser limpos em sentido único, utilizando pano ou esponja e, após, secos com panos limpos.

- Todos os instrumentais odontológicos devem ser previamente descontaminados com detergente enzimático antes da limpeza, embalagem e esterilização. A esterilização por meio físico deve ocorrer com uso de calor úmido (autoclave), conforme orientações do fabricante.

Fontes: Agência Nacional de Vigilância Sanitária; Conselho Federal de Odontologia; Ministério da Saúde

A estrutura curricular do curso de Odontologia vem trabalhando com diferentes perspectivas de olhar o mundo e a formação em saúde. As perspectivas dos indicadores sociais, realidades populacionais e programas públicos de saúde possibilitam a formação de cirurgiões- dentistas com uma visão generalista, humanista, crítica e reflexiva, capacitados ao exercício de atividades referentes à saúde bucal da população, com base no rigor técnico e científico ${ }^{35}$.

No atual contexto pandêmico, os desafios relacionados à educação para escolas 
odontológicas, bem como seus hospitais afiliados, são significativos ${ }^{36}$. Diferente da educação médica, o ensino em Odontologia exige uma alta demanda de atividades práticas em clínicas odontológicas que reúnem muitos estudantes em ambientes físicos coletivos, o que não pode ser substituído por atendimentos realizados na modalidade de telessaúde, conforme medida adotada em alguns cursos de Medicina do país ${ }^{37}$.

Os cursos de Odontologia estão à frente do obstáculo de desenvolver, com agilidade e criatividade, meios para garantir a educação contínua da futura força de trabalho odontológica ${ }^{7}$. Novos planejamentos de contingência estão sendo desenvolvidos para serem executados no retorno às atividades acadêmicas, e enquanto perduram a suspensão das aulas presenciais, o ensino remoto é utilizado para gerar reflexões para a futura prática na clínica odontológica e no campo da extensão universitária.

Corroborando com a Association for Dental Education in Europe (AADEE), American Dental Education Association (ADEA) e a Portaria 343 do Ministério da Educação (MEC) de 17 de março de 2020, a Associação Brasileira de Ensino Odontológico (ABENO) reconhece que as aulas remotas representam uma estratégia temporária para o ensino da Odontologia enquanto a situação de pandemia do novo COVID-19 permanecer $^{28}$. Em nota, a ABENO ainda reafirma seu compromisso em salvaguardar os direitos dos estudantes à formação de qualidade, à voz nos processos decisórios institucionais e à equidade no acesso aos recursos digitais utilizados neste período $^{28}$.

A suspensão da educação presencial e atividades clínicas de atendimento ao paciente por um período indefinido é um obstáculo enorme e sem precedentes no campo da educação odontológica. A interrupção de atividades nas clínicas universitárias possibilitou uma mudança provisória do currículo tradicional para um modelo de ensino remoto em alguns cursos de Odontologia do país ${ }^{7}$. Por sua vez, a aprendizagem virtual deve ser empregada quando apropriada, com o adequado treinamento do corpo docente e amplo acesso às tecnologias disponíveis para os alunos ${ }^{5}$.

Os ambientes virtuais de aprendizagem, como o Moodle, Google-for-education e Classroom, são amplamente utilizados para o ensino à distância $(\mathrm{EaD}) \mathrm{e}$ foram criados com uma proposta de "aprender em colaboração", em um ambiente online. Entre os recursos e atividades disponíveis nessas plataformas, destacam-se os fóruns de opiniões, chats, questionários estruturados, exercícios didáticos, além de salas para reuniões coletivas por videoconferência ${ }^{38}$. Durante o período de surto da pandemia, essas ferramentas podem ser utilizadas para a realização de palestras online, estudos de casos e tutoriais de aprendizagem baseados em problemas clínicos, incentivando o autoaprendizado ${ }^{7}$.

No Brasil, cerca de $90 \%$ das Universidades Federais optaram por não aderir integralmente ao ensino remoto, enquanto $78 \%$ das instituições privadas o adotaram durante o surto da pandemia. Outras instituições de ensino, embora mantenham algum tipo de atividade educacional a distância, salientam que essas não substituem o conteúdo educativo regular ${ }^{39}$.

Uma das principais dificuldades do $\mathrm{EaD}$ em Universidades Federais é a democratização do acesso dessa tecnologia aos alunos, considerando que a maioria desses não tem recursos adequados para acompanhar os conteúdos virtuais em seus lares. A equidade no acesso estudantil aos recursos de infraestrutura e tecnologia pode influenciar diretamente nas ações de ensino executadas pelos cursos de Odontologia neste período.

São evidentes as dificuldades que essa parcela do corpo discente encontra para acesso a hardwares adequados para atividades $\mathrm{EaD}$, bem como ao acesso - de boa qualidade - à rede mundial de computadores. Os dados da V Pesquisa 
Nacional de Perfil Socioeconômico e Cultural dos (as) Graduandos (as) das Instituições de Ensino Superior ressaltam as disparidades entre os estudantes brasileiros, sendo que a metade deles pertencem a famílias de baixa renda, não possuem acesso à internet e também não contam com espaços físicos específicos para estudar em casa ${ }^{40}$. Divulgada em 2019, uma pesquisa de abordagem a nível nacional apontou que $58 \%$ dos domicílios no Brasil não têm acesso a computadores e $33 \%$ não dispõem de internet. Entre as classes mais baixas, o acesso é ainda mais restrito, o que vai ao encontro dos dados encontrados entre os universitários de instituições públicas ${ }^{41}$.

Além disso, diversas condições familiares e sociais impactam a diversidade e a capacidade de estudo, desde a saúde física e mental em tempos de isolamento e pandemia aos espaços e condições de estudo domésticas, passando pelas diversas tarefas dos estudantes e docentes e suas condições de habitação ${ }^{42}$.

A utilização dessas tecnologias na educação ainda é considerada uma novidade, visto que grande parte do corpo docente opta pelos métodos tradicionais de ensino. Muitos professores universitários não passaram por uma formação adequada que envolvesse algum tipo de aprendizado com o uso dessas plataformas virtuais, da mesma forma como muitos também não foram devidamente capacitados para aplicar suas metodologias de ensino utilizando esses espaços ${ }^{43}$. Nesse sentido, considerando o fato que a interrupção das aulas presenciais pela pandemia de COVID-19 ocorreu de forma abrupta e inesperada, e que existe a necessidade de educação contínua dos estudantes, as instituições de ensino superior do país também enfrentam o desafio de capacitar seu quadro docente para a realização dessas atividades.

O momento de distanciamento social possibilitou a adaptação e novas formas de disseminar conhecimento. A Universidade Federal do Rio Grande do Sul (UFRGS), Universidade
Federal de Campina Grande (UFCG) e Universidade Federal de Uberlândia (UFU) recentemente desenvolveram cursos on-line voltados à capacitação docente e inovação dos procedimentos didático-pedagógicos no processo de ensino-aprendizagem na modalidade EaD. De maneira geral, os cursos são compostos por vivências de atividades no ambiente virtual, experimentações com a configuração das ferramentas e materiais de apoio.

A Universidade Tiradentes (UNIT), uma instituição particular de referência no Nordeste Brasileiro, tem realizado diversas iniciativas que partem do curso de Odontologia. Dentre eles, o trabalho intensivo das ligas acadêmicas com tutoria especial de seus professores, bem como parcerias com os Programas de Pós-graduação para apresentações em eventos online com temáticas relacionadas ao contexto do COVID-19. A UNIT foi a pioneira na utilização massiva da plataforma Google For Education no Brasil e com isso oferta a todos seus alunos acesso ilimitado aos conteúdos da plataforma, sem custo na franquia de dados celulares.

No sul do país, os cursos de Odontologia da Pontifícia Universidade Católica do Rio Grande do Sul (PUC-RS), Universidade Luterana do Brasil (ULBRA) e Universidade Católica de Pelotas (UCPel) estão cumprindo suas cargas horárias obrigatórias por meio de atividades teóricas via ambiente de aprendizagem virtual. Os exames avaliativos e trabalhos complementares também estão sendo realizados utilizando essas ferramentas.

Embora essas metodologias sejam promissoras, é interessante destacar que essa não é a realidade dos cursos de Odontologia de instituições públicas do país. A maioria dessas escolas estão com as suas atividades clínicas interrompidas, com materiais didáticos virtuais sendo repassados de forma complementar, para que assim que retornarem, possam prosseguir com o 
conteúdo acadêmico programático de forma regular.

A partir disso, é notável que os cursos de Odontologia devem desenvolver suas atividades de acordo com o contexto social de seus estudantes e professores. Aplicativos para celulares poderiam ser utilizados para estabelecer um canal aberto de comunicação com os acadêmicos ${ }^{7}$. Além disso, para a transmissão de informações recentes sobre as doenças infecciosas, métodos preventivos, bem como para a avaliação do grau de acesso desses estudantes aos recursos tecnológicos disponíveis em seus domicílios.

Diante do medo e da ansiedade demonstrados pela comunidade odontológica em relação à COVID-19, é crucial que mecanismos e estratégias psicológicas de enfrentamento sejam criados para manter a calma e a correta execução da prática profissional. O receio que os cirurgiõesdentistas têm em se infectar com a COVID19 pode ser reduzido com o seguimento meticuloso das recomendações de biossegurança.

O currículo odontológico vigente discute amplamente o controle básico de infecções, especialmente os riscos de infecções transmitidas pelo sangue, como os vírus da Imunodeficiência Humana e da Hepatite B, e recomenda precauções universais para prevenção de doenças transmitidas pelo sangue. Entretanto, as infecções transmitidas por gotículas respiratórias e pela geração de aerossóis parecem ser raramente abordadas ${ }^{36}$.

Mais uma vez se enfatiza que essas medidas de prevenção devem ser perpetuadas na rotina clínica, de forma que a disseminação desses aerossóis seja controlada por protocolos rígidos de biossegurança. Com isso, é importante utilizar as atividades remotas de ensino para o treinamento dos estudantes para a correta utilização de equipamentos de proteção individual (EPIs) e realização dos protocolos, ajudando-os a desenvolver conhecimentos e atitudes adequadas no controle da infecção.
Também é fundamental que as escolas utilizem esse momento para trabalhar conhecimentos específicos sobre as principais desordens bucais que atingem a população brasileira, visto que após o retorno das atividades, a demanda reprimida precisará de atendimento odontológico para o cuidado das complicações orais que se acumularam neste período. Perez et al. (2020) alertaram sobre a importância da educação continuada em câncer bucal durante surto de COVID-19 ${ }^{44}$, considerando principalmente que o diagnóstico tardio dessa condição pode implicar num pior prognóstico do caso e, até mesmo, resultar em alta mortalidade e morbidade ${ }^{27}$. Portanto é essencial manter os estudantes e profissionais atualizados, além de prepará-los com foco na atenção primária, na rápida identificação e diagnóstico de pacientes após retornar à prática clínica.

As instituições devem se preparar no sentido de previsão de riscos e organização de seus planos de contingência que não incluam somente $o$ momento atual. Essas medidas, após o contexto de pandemia, devem ser seguidas e respeitadas no ambiente clínico odontológico, assim como os aspectos relacionados à biossegurança e proteção de alunos, professores e funcionários. $\mathrm{O}$ planejamento para a futura prática clínica da Odontologia em ambientes coletivos deve seguir rigidamente as diretrizes do Conselho Federal de Odontologia, as orientações dos Planos de Contingência de Manejo Clínico e de Infecção Humana por COVID-19 do Ministério da Saúde, e as recomendações do Ministério da Educação.

Para melhorar a educação sobre contenção de doenças infecciosas, as escolas de Odontologia também precisarão considerar a adoção de uma política de monitoramento de controle de infecção de alto padrão, por meio do estabelecimento de comitês e unidades de controle de infecção. Esses comitês devem ter o envolvimento ativo do corpo docente, discentes e dos dirigentes, possibilitando 
melhores condições sanitárias, de assepsia, de controle de risco biológico e de descarte de resíduos infectantes.

Antes mesmo do surgimento do COVID-19, nos surtos anteriores de SARS-CoV e Mers-CoV, a Odontologia já havia reformulado suas orientações em biossegurança para evitar a propagação dessas doenças no consultório odontológico. $\mathrm{O}$ controle de infecção pela limitação aérea de aerossóis não é uma novidade, mas aparentemente só é utilizado quando há maiores riscos de contaminação ${ }^{45,46}$. Com isso, é questionável qual será de fato o padrão necessário de EPIs e protocolos de segurança após a pandemia de COVID-19. É evidente que deverá ocorrer uma reorganização geral dos atendimentos e da infraestrutura das clínicas, principalmente no que diz respeito a rotatividade de estudantes, funcionários e pacientes nas dependências dos cursos, assim como na disposição dos consultórios coletivos em relação ao espaçamento e isolamento de unidades dentárias e no controle da circulação do ar condicionado.

\section{CONCLUSÃO}

Várias agências, universidades e empresas estão trabalhando arduamente para desenvolver testes mais rápidos e buscar medidas para prevenção e tratamento da infecção por COVID19. Enquanto isso não é possível, os profissionais e os serviços de saúde bucal devem estar atentos às atuais recomendações que norteiam a prática odontológica, baseando-se nas publicações oficiais do Conselho Federal de Odontologia, da Agência Nacional de Vigilância Sanitária e do Ministério da Saúde. As escolas de Odontologia devem se atualizar quanto a realidade atual, incorporando variações tecnológicas no ensino tradicional, trazendo alternativas remotas permanentemente em seus currículos. Os docentes podem se capacitar e aprimorar suas habilidades didáticas, bem como os estudantes fazerem uso dessa tecnologia para a construção de conhecimento. Ainda, a educação em controle de infecção precisa ser estimulada e ampliada no currículo dos cursos de Odontologia e os estudantes devem ser treinados adequadamente para a prevenção de infecções cruzadas, de modo que tenham o conhecimento e a capacidade de causar impacto na comunidade, ajudando-a durante a pandemia.

\section{ABSTRACT \\ Coronavirus disease 2019: emerging challenges and Brazilian dental education}

Coronavirus disease (COVID-19) emerged in China in late 2019, spreading rapidly to more than 216 countries. Due to the characteristics of the dental environments and procedures, there is a greater risk of cross-infection between the oral health team and the users of this service. For dental offices, dental schools, and their associated hospitals, located in areas (potentially) affected by COVID-19, rigorous and effective infection control protocols have being urgently developed by the competent regulatory agencies, both nationally and internationally. In addition, the pandemic had an immediate and dramatic impact on dental education, as institutions are now facing the challenge of reorganizing their infrastructure and teaching methods to face the possible consequences of this new reality, preserving and fostering continuous progress future professionals. In this sense, the objective of this study is to present important information related to the new acute respiratory syndrome caused by coronavirus- 2 and its impact on Dentistry, addressing the main biosafety guidelines that must be adopted in clinical care, as well as discussing changes in Brazilian dental education. against the COVID-19 pandemic.

Descriptors: COVID-19. Coronavirus infections. Infection Control. Dentistry. Dental Education.

\section{REFERÊNCIAS}

1. Guan W-J, Ni Z-Y, Hu Y, Liang W-h, Ou C$\mathrm{Q}, \mathrm{He} \mathrm{J}-\mathrm{X}$, et al. Clinical characteristics of coronavirus disease 2019 in China. N Engl J Med. 2020;382(18):1708-20. 
2. Mahase E. Coronavirus covid-19 has killed more people than SARS and MERS combined, despite lower case fatality rate. BMJ. 2020;368:641.

3. Amanat F, Krammer F. SARS-CoV-2 vaccines: status report. Immunity. 2020. [Acesso em: 23 de maio de 2020]. Disponível em: https://www.ncbi.nlm.nih. gov/pmc/articles/PMC7136867/.

4. Maia ABP. The Challenges of Dentistry in the time of COVID-19. Rev Bras Odontol. 2020;77:15-8.

5. Meng L, Hua F, Bian Z. Coronavirus disease 2019 (COVID-19): emerging and future challenges for dental and oral medicine. $\mathbf{J}$ Dent Res. 2020;99(5):481-7.

6. Iyer P, Aziz K, Ojcius DM. Impact of COVID-19 on dental education in the United States. J Dent Educ. 2020. [Acesso em: 23 de maio de 2020]. Disponível em: https://onlinelibrary.wiley.com/doi/epdf/10. 1002/jdd.12163.

7. Quinn B, Field J, Gorter R, Akota I, Manzanares MC, Paganelli C, et al. COVID19: the immediate response of european academic dental institutions and future implications for dental education. Eur J Dent Educ. 2020. [Acesso em: 23 de maio de 2020]. Disponível em: https://pubmed.ncbi. nlm.nih.gov/32394605/.

8. Sabino-Silva R, Jardim ACG, Siqueira WL. Coronavirus COVID-19 impacts to dentistry and potential salivary diagnosis. Clin Oral Invest. 2020:1619-21.

9. Brasil. Ministério da Saúde. Nota Técnica $N^{\circ}$ 9/2020 - CGSB. Atendimento Odontológico No Sus Durante A Epidemia Do Novo Coronavírus. [Acesso em: 23 de maio de 2020]. Disponível em: http://189.28.128. 100/dab/docs/portaldab/documentos/COVI D_19_ATENDIMENTO\%20ODONTOLO GICO_SUS_APS_20200319_ver001.pdf.
10. Werneck, GL, Carvalho, MS. A pandemia de COVID-19 no Brasil: crônica de uma crise sanitária anunciada. Cad. Saúde Pública, 2020;36(5): 00068820. [Acesso em: 26 de maio de 2020]. Disponível em: https://www.scielo.br/pdf/csp/v36n5/1678 -4464-csp-36-05-e00068820.pdf.

11. Guo H, Zhou Y, Liu X, Tan J. The impact of the COVID-19 epidemic on the utilization of emergency dental services. J Dent Sci. 2020. [Acesso em: 23 de maio de 2020]. Disponível em: https://pubmed. ncbi.nlm.nih.gov/32296495/.

12. Lu H, Stratton CW, Tang YW. Outbreak of Pneumonia of unknown etiology in Wuhan China: the mystery and the miracle. J Med Virol. 2020; 92(4):401-2.

13. Lu R, Zhao X, Li J, Niu P, Yang B, Wu H, et al. Genomic characterisation and epidemiology of 2019 novel coronavirus: implications for virus origins and receptor binding. Lancet. 2020;395(10224):565-74.

14. Amirian ES. Potential fecal transmission of SARS-CoV-2: current evidence and implications for public health. Int J Infect Dis. 2020;95:363-70.

15. Bai Y, Yao L, Wei T, Tian F, Jin D-Y, Chen $\mathrm{L}$, et al. Presumed asymptomatic carrier transmission of COVID-19. JAMA. 2020;323(14):1406-7.

16. Sohrabi C, Alsafi Z, O’Neill N, Khan M, Kerwan A, Al-Jabir A, et al. World Health Organization declares global emergency: A review of the 2019 novel coronavirus (COVID-19). Int J Surg. 2020; 76:71-6.

17. World Health Organization (WHO). Coronavirus disease (COVID-19). 2020. [Acesso em: 23 de maio de 2020]. Disponível em: https://covid19.who.int/.

18. Lo Giudice R. The Severe Acute Respiratory Syndrome Coronavirus-2 (SARS CoV-2) in Dentistry. Management of Biological Risk in Dental Practice. Int J Environ Res Public 
Health. 2020;17(9):3067.

19. Wang D, Hu B, Hu C, Zhu F, Liu X, Zhang $\mathrm{J}$, et al. Clinical characteristics of 138 hospitalized patients with 2019 novel coronavirus-infected pneumonia in Wuhan, China. JAMA. 2020;323(11):1061-9.

20. Alharbi A, Alharbi S, Alqaidi S. Guidelines for dental care provision during the COVID-19 pandemic. Saudi Dent J. 2020; 32(4):181-6.

21. Ong SWX, Tan YK, Chia PY, Lee TH, Ng OT, Wong MSY, et al. Air, surface environmental, and personal protective equipment contamination by severe acute respiratory syndrome coronavirus 2 (SARSCoV-2) from a symptomatic patient. JAMA. 2020; 323(16):1610-2.

22. Chowell G, Abdirizak F, Lee S, Lee J, Jung E, Nishiura $\mathrm{H}$, et al. Transmission characteristics of MERS and SARS in the healthcare setting: a comparative study. BMC Med. 2015;13(1):210.

23. Van Doremalen N, Bushmaker T, Morris DH, Holbrook MG, Gamble A, Williamson BN, et al. Aerosol and Surface Stability of SARSCoV-2 as Compared with SARS-CoV-1. N Engl J Med. 2020;382(16):1564-7.

24. Peng X, Xu X, Li Y, Cheng L, Zhou X, Ren B. Transmission routes of 2019-nCoV and controls in dental practice. Int J Oral Sci. 2020;12(1):1-6.

25. Khader Y, Al Nsour M, Al-Batayneh OB, Saadeh R, Bashier H, Alfaqih M, et al. Dentists' Awareness, Perception, and Attitude Regarding COVID-19 and Infection Control: Cross-Sectional Study Among Jordanian Dentists. JMIR Public Health Surveill. 2020;6(2):e18798.

26. Kamate SK, Sharma S, Thakar S, Srivastava D, Sengupta K, Hadi AJ, et al. Assessing Knowledge, Attitudes and Practices of dental practitioners regarding the COVID-19 pandemic: A multinational study. Dent Med
Probl. 2020;57(1):11-7.

27. Arduino PG, Conrotto D, Broccoletti R. The outbreak of Novel Coronavirus disease (COVID-19) caused a worrying delay in the diagnosis of oral cancer in north-west Italy: The Turin Metropolitan Area experience. Oral Dis. 2020. [Acesso em: 23 de maio de 2020]. Disponível em: https://onlinelibrary. wiley.com/doi/full/10.1111/odi.13362.

28. Associação Brasileira de Ensino Odontológico (ABENO). Posicionamento da abeno sobre a substituição das aulas presenciais por aulas em meios digitais nos cursos de odontologia, enquanto durar a situação de pandemia covid-19. [Acesso em: 23 de maio de 2020]. Disponível em: https://drive.google.com/file/d/1_9mXrwbK Yy72zvirIgbbmgwlaPgyRmf9/view.

29. Agência Nacional de Vigilância Sanitária (ANVISA). Nota técnica GVIMS/GGTES/ ANVISA $N^{\circ}$ 04/2020. Orientações para serviços de saúde: medidas de prevenção e controle que devem ser adotadas durante a assistência aos casos suspeitos ou confirmados de infecção pelo novo coronavírus. 2020. [Acesso em: 23 de maio de 2020]. Disponível em: http://portal. anvisa.gov.br/documents/33852/271858/No ta+T\%C3\%A9cnica+n+04-2020+GVIMSGGTES-ANVISA/ab598660-3de4-4f148e6f-b9341c196b28.

30. Conselho Federal de Odontologia (CFO). Manual de Boas Práticas em Biossegurança para Ambientes Odontológicos. 2020. [Acesso em: 23 de maio de 2020]. Disponível em: http://website.cfo.org.br/ covid19-manual-de-boas-praticas-em-bios seguranca-para-ambientes-odontologicos-elancado-com-apoio-institucional-do-cfo/.

31. American Dental Association (ADA). ADA Interim Guidance for Minimizing Risk of COVID-19 Transmission. 2020. [Acesso em: 
22 de maio de 2020]. Disponível em: https://www.ada.org/ /media/CPS/Files/COVI D/ADA_COVID_Int_Guidance_Treat_Pts.pdf ?utm_source=adaorg\&utm_medium $=$ covi\%20 d-resources-lp\&utm_content=cv-pm-ebd-inter im-response\&utm campaign=covid-19.

32. Centers of Disease Control and Prevention (CDC). Interim Infection Prevention and Control Guidance for Dental Settings During the COVID-19. 2020. [Acesso em: 22 de maio de 2020]. Disponível em: www.cdc.gov/coronavirus/2019-ncov/hcp/ dental-settings.html.

33. Arantes DC, Hage CA, Nascimento LS, Pontes FSC. Biossegurança aplicada à Odontologia na Universidade Federal do Pará, Cidade de Belém, Estado do Pará, Brasil. Rev Pan-Amaz Saúde. 2015;6:11-8.

34. Resende KKM, Neves LF, Nagib LdRC, Martins LJO, Costa CRR. Educator and student hand hygiene adherence in dental schools: a systematic review and metaanalysis. J Dent Educ. 2019;83(5):575-84.

35. Brasil. Ministério da Educação. Conselho Nacional de Educação: Diretrizes Curriculares Nacionais do Curso de Graduação em Odontologia. 2002. [Acesso em: 23 de maio de 2020]. Disponível em: http://portal.mec.gov.br/cne/arquivos/pdf/C ES032002.pdf.

36. Ghai S. Are dental schools adequately preparing dental students to face outbreaks of infectious diseases such as COVID-19? J Dent Educ. 2020. [Acesso em: 23 de maio de 2020]. Disponível em: https://onlinelibra ry.wiley.com/doi/full/10.1002/jdd.12174.

37. Goh P-S, Sandars J. A vision of the use of technology in medical education after the COVID-19 pandemic. Med Ed Publish. 2020. [Acesso em: 23 de maio de 2020]. Disponível em: https://www.mededpu blish.org/manuscripts/2943.
38. Soto U, Mayrink MF, Gregolin IV. Linguagem, educação e virtualidade: SciELO-Editora UNESP; 2009.

39. Brasil. Ministério da Educação. Coronavírus: Portal de Monitoramento das Instituições de Ensino. [Acesso em: 23 de maio de 2020]. Disponível em: http://portal.mec.gov.br/coronavirus/.

40. Associação Nacional dos Dirigentes das Instituições Federais de Ensino Superior (ANDIFES). V Pesquisa Nacional de Perfil Socioeconômico e Cultural dos (as) Graduandos (as) das IFES. 2018. [Acesso em: 23 de maio de 2020]. Disponível em: http://www.andifes.org.br/wp-content/uplo ads/2019/05/V-Pesquisa-do-Perfil-Socioec on\%C3\%B4mico-dos-Estudantes-de-Gra dua\%C3\%A7\%C3\%A3o-das-Universida des-Federais-1.pdf.

41. Comitê Gestor da Internet no Brasil. Pesquisa sobre o uso das Tecnologias de Informação e Comunicação nos domicílios brasileiros - TIC Domicílios 2018. [Acesso em: 22 de maio de 2020]. Disponível em: https://www.cgi.br/media/docs/publicacoes/ 2/12225320191028-tic_dom_2018_livro_ eletronico.pdf.

42. Acs G, Lodolini G, Kaminsky S, Cisneros GJ. Effect of nursing caries on body weight in a pediatric population. Pediatr Dent. 1992;14(5):302-5.

43. Castro MASN. Processos de auto-regulação da aprendizagem: impacto de variáveis académicas e sociais. Braga, Portugal. [Dissertação]. Mestrado em Psicologia Escolar]. Universidade do Minho, 2007.

44. Avila BG. Formação docente para a autoria nos mundos virtuais: uma aproximação do professor às novas demandas tecnológicas. [Tese]. Doutorado em Informática na Educação. Universidade Federal do Rio Grande do Sul, 2016. 
45. Cruz-Perez DE, Passos KKM, Machado RA, Martelli-Junior H, Bonan PRF. Continuing education in oral cancer during coronavirus disease 2019 (covid-19) outbreak. Oral Oncol. 2020;105:104713.

46. Smales F, Samaranyake L. Maintaining dental education and specialist dental care during an outbreak of a new coronavirus infection. Part 1: A deadly viral epidemic begins. Br Dent J. 2003;195(10):557-61.
47. Al-Tawfiq JA, Perl TM. Middle East respiratory syndrome coronavirus in healthcare settings. Curr Opin Infect Dis. 2015;28(4):392-6.

\section{Correspondência para:}

Vanessa dos Santos Viana

e-mail: vanessaodontopediatria@gmail.com Rua Siriri, 263 / Sala 101

49010-390 Aracaju/SE 